\title{
Laparoscopic appendicectomy under spinal anaesthesia
}

\author{
Dr. Manish K. Singh, Dr. Aloke Kumar, Dr. Prof. Subrata Nag
}

\begin{abstract}
Nowadays laparoscopic appendicectomy ( LA) is gaining popularity due to its certain benefits over the open technique. General anesthesia with positive pressure ventilation is the preferred mode of anesthesia in this technique. There are limited data about LA under spinal anesthesia. This study was designed to evaluate $L A$ under spinal anesthesia for uncomplicated appendicitis .

In this prospective study, 35 consecutive patients of ASA grade I or II, with a mean age of 22.5 years and mean BMI of $18.35 \mathrm{~kg} / \mathrm{m}^{2}$, suffering from acute appendicitis, were included. All patients were informed about spinal anesthesia in detail. The patients were informed about the risk of conversion to general anesthesia, and all patients provided informed consent. Standard laparoscopic technique was applied to all patients. Simple questionnaire forms were developed for patients to provide comments about the operation. All the patients received ondansetron, diazepam, and pentazocine as premedication. Monitored anesthesia care was given.
\end{abstract}

The operation was completed laparoscopically on 33 patients, while 2 patients were converted for open technique. None of the patients developed cardiopulmonary problems other than transient hypotension.. None of the patients required conversion to general anaesthesia.Seventeen patients developed mild right shoulder. Intravenous tramadol hudrochloride $(10 \mathrm{mg})$ was needed in 16 patients due to severe right shoulder pain. Five patients complained about postural headache in postoperative period. Mean operative time was 25.35 minutes. In post operative period median pain score at $4 \mathrm{hr}$ was 1.5 (range, 0-5), at 8 hr it was 1 (range, 0-6), and at $24 \mathrm{hr}$ it was 1 (range, 0-4). No one patient developed wound infection or any other complication. All thirty three patients were discharged after $24 \mathrm{hr}$. All of the patients' answers to the questions regarding the comfort of operation were "well" at the 1-month postoperative evaluation.

Laparoscopic appendicectomy with low-pressure $\mathrm{CO}_{2}$ pneumoperitoneum can be successfully and safely performed under spinal anesthesia. Furthermore, it seems that spinal anesthesia is associated with minimal postoperative pain and at least an equally good recovery as with general anesthesia.

Keywords: Laparoscopic appendicectomy, spinal anesthesia, monitored anesthesia care

\section{Introduction}

Laparoscopic appendicectomy (LA) is the most commonly performed intra-abdominal operation. Semm[1] first introduced the laparoscopic method for appendicectomy in the early 1980s. Since then laparoscopic appendicectomy was made popular by various surgeons and preferred over the open method due to its inherent advantages.[2] General anesthesia with positive pressure ventilation is the preferred mode of anesthesia in this technique. Regional anesthesia has not been used as the sole anesthetic procedure other than in the scenario of a patient at high risk to undergo laparoscopic appendicectomy with $\mathrm{CO}_{2}$ pneumoperitoneum under general anesthesia. Various study already established the feasibility and safety of spinal anaesthesia for laparoscopic surgery.[3,18] The aim of our study is to evaluate the feasibility and safety of spinal anaesthesia for laparoscopic appendicectomy. As a pilot study we included a selected group of patients with low body mass index (BMI) and uncomplicated appendicitis.

\section{Materials And Methods}

We conducted a prospective study over a twelve-month period where LA was performed on 35 patients (twenty one female and fourteen male) of ASA grade I or II, who presented with acute appendicitis. Mean age of patients was 22.5 years ranging from 18 to 35 years, with a mean BMI of $18.35 \mathrm{~kg} / \mathrm{m}^{2}$ ranging from 15.18 to $25.25 \mathrm{~kg} / \mathrm{m}^{2}$. (Table I ) Inclusion criteria included — pain in the right iliac fossa, with muscle guarding, tenderness at McBurney's point, vomiting, fever, leukocytosis, and age more than 18 years. All the patients had a plain abdominal radiograph, routine blood tests, and a sonographic examination. Patients with generalized peritonitis, appendicular abscess or perforation, and a palpable mass were excluded from the study. The patients who were found to have gangrenous or perforated appendicitis under laparoscopic view were excluded from this study and converted into the open technique. All patients were informed about spinal anesthesia in detail. The patients were informed about the risk of conversion to general anesthesia, and all patients provided informed consent. Simple questionnaire forms were developed for patients to provide comments about the operation. 
Preoperatively about $500 \mathrm{ml}$ of Ringer's lactate solution was infused in all patients except patients with hypertension. Intravenous antibiotic (ceftriaxone) was given. Standard spinal puncture with $26 \mathrm{G}$ spinal needle was done between L1 and L2 spaces at right lateral position. Only $3.5 \mathrm{ml}$ of $0.5 \%$ bupivacaine heavy was given. Patient was kept in right lateral position for about $30 \mathrm{sec}$ and then turned to supine with head end of the table tilted down $10-15^{\circ}$ with a pillow under the head. Pantoprazole $(20 \mathrm{mg})$, Ondansetron $(100 \mu \mathrm{g} / \mathrm{kg}$.), diazepam $(200 \mu \mathrm{g} / \mathrm{kg}$.), and pentazocine (500 $\mu \mathrm{g} / \mathrm{kg}$ ) were used as premedication. Monitored anesthesia care (MAC) was given. All patients were monitored for blood pressure (non-invasive), heart rate, electrocardiogram, and oxygen saturation by pulse oximetry. The pneumoperitoneum was created using carbon-di-oxide and the pressure was kept at $9-10 \mathrm{mmHg}$. The table was kept in the Trendelenburg position with $15^{\circ}$ left tilt. A $0^{\circ}$ telescope was introduced through the $10-\mathrm{mm}$ umbilical port for complete examination of the abdomen. Two $5-\mathrm{mm}$ ports placed in supra pubic area below the pubic hair line as working port. The appendix is then identified and lifted by a non-traumatic grasper. The mesoappendix was coagulated with bipolar cautery and divided. The base of the appendix was tied with endoloop of vicryl 1.0 at the ileo-cecal junction and divided. The appendix was retrieved out in a plastic bag through umbilical port. The umbilical port site wound was closed with 1.0 Vicryl. The patients were started orally after $4 \mathrm{hrs}$ of operation and solid food on the next day. Patients were called for a revisit after a week for follow-up. Operative time, conversion, complications, post operative pain ,hospital stay \&cosmetic results were analyzed.

\section{Results}

The operation was completed laparoscopically on 33 patients, while 2 patients were converted for open technique due to inflammatory adhesion. (Table I) None of the patients had cardiopulmonary problems other than transient hypotension $(<20 \%$ of pre anaesthesia value) in 12 patients during surgery which was managed with intravenous fluid. None of the patients required conversion to general anaesthesia. Seventeen patients developed mild right shoulder pain which was managed with gentle massage of right shoulder. Intravenous tramadol hydrochloride $(10 \mathrm{mg})$ was needed in 16 patients due to severe right shoulder pain. Five patients complained about postural headache in post operative period which was managed with analgesics. Mean operative time was 25.35 minutes (range 18-45 minutes). In post operative period median pain score at $4 \mathrm{hr}$ was 1.5 (range, $0-5$ ), at $8 \mathrm{hr}$ it was 1 (range, $0-6$ ), and at $24 \mathrm{hr}$ it was 1 (range, $0-4$ ). No one patient developed wound infection or any other complication. All thirty three patients were discharged after $24 \mathrm{hr}$. Almost all patients satisfied with their cosmetic results. All of the patients' answers to the questions regarding the comfort of operation were "well" at the 1-month postoperative evaluation.

\section{Discussion}

Laparoscopic appendicectomy is the gold standard for treatment of uncomplicated appendicitis. General anesthesia is regarded as safe anesthesia for laparoscopic surgery in most of the cases till now. Regional anesthesia has not been used as the sole anesthetic procedure other than in the scenario of a patient at high risk to undergo laparoscopic appendicectomy with $\mathrm{CO}_{2}$ pneumoperitoneum under general anesthesia.

Single puncture spinal anesthesia can be an easier technique than general anesthesia.[3] Monitoring of patients under spinal anesthesia is easier than general anesthesia. Complication of endotracheal intubations like damage to oral cavity, teeth, sore throat, and aspirations, failure of intubations are absent in spinal anesthesia. Cost of spinal anesthesia is far less than general anesthesia. Nausea and vomiting are less with spinal anesthesia.[3-15]

Laparoscopic cholecystectomy with low-pressure pneumo-peritoneum under spinal anesthesia is effective in patients with COPD, who are unfit for general anesthesia.[7,8].Various study already established the feasibility and safety of spinal anaesthesia for laparoscopic surgery.[3,18] Laparoscopic appendicectomy can be successfully performed under combined spinal epidural anesthesia without any significant complications.[16] Hypotension is a problem of spinal anesthesia, which can be overcome by preloading with fluids.[9,15]. In this study 12 patients developed transient hypotension $(<20 \%$ of pre anaesthesia value) which was managed with extra intravenous fluid and no one patient required injection of mephentermine . Laparoscopic surgery under general anesthesia is associated with hypertensive episodes; but under spinal anesthesia, there were no such episodes of hypertension in any patients. Vasodilatations under spinal anesthesia was also preventive against hypertensive episodes during operation.[3,5]

Under regional anesthesia the respiratory mechanism remains intact, and diaphragm the main inspiratory muscle is unaffected allowing the patient to adjust minute ventilation without any significant changes in ventilatory parameters or $\mathrm{CO}_{2}$ levels.[7] In a study conducted by Ciofolo et al., the ventilatory measurements and arterial blood gases were maintained within normal limits at different stages during laparoscopy under epidural anesthesia.[17] Respiration rate was increased to washout carbon-di-oxide.[3,5] Here, as we operated under low-pressure $(9-10 \mathrm{mmHg})$ pneumo-peritoneum, incidences of hypercarbia producing hypertensive episodes were negligible. 
Per-op mild shoulder pain can be managed by finger massaging over right shoulder, using low-pressure pneumoperitoneum and clearing-out of smoke due to diathermy at the earliest. Lower rate of carbon-di-oxide inflow (1-2 L) during initial phase of inflation can avoid shoulder pain. Post-op shoulder pain can be avoided by near complete evacuation of pneumoperitoneum and by elevation of foot end of the table.[18] Severe right shoulder pain can be managed with injection of tramadol hydrochloride or fentanyl. Here, we managed severe shoulder pain in 16 patients with injection of tramadol hydrochloride $(10 \mathrm{mg})$.

Low-pressure pneumoperitoneum and spinal anesthesia cause no problem for space during operation.

Complications of appendicectomy are similar to standard laparoscopic appendicectomy under general anesthesia.

\section{Conclusion:}

Laparoscopic appendicectomy with low-pressure $\mathrm{CO}_{2}$ pneumoperitoneum can be successfully and safely performed under spinal anesthesia. Furthermore, it seems that spinal anesthesia is associated with minimal postoperative pain and at least an equally good recovery as with general anesthesia.

\section{References}

[1]. Semm K. Endoscopic appendectomy. Endoscopy. 1983;15:59-64. [PubMed

[2]. Li X, Zhang J, Sang L, Zhang W, Chu Z, Li X, et al. Laparoscopic versus conventional appendectomy--a meta-analysis of randomized controlled trials. BMC Gastroenterol. 2010;10:129. [PMC free article][PubMed]

[3]. Yuksek YN, Akat AZ, Gozalan U, Daglar G, Pala Y, Canturk M, et al. Laparoscopic cholecystectomy under spinal anesthesia. Am J Surg. 2008;195:533-6. [PubMed]

[4]. Sinha R, Gurwara AK, Gupta SC. Laparoscopic surgery under spinal anesthesia. JSLS. 2008;12:133-8. [PMC free article] [PubMed]

[5]. van Zundert AA, Stultiens G, Jakimowicz JJ, Peek D, van der Ham WG, Korsten HH, et al. Laparoscopic cholecystectomy under segmental thoracic spinal anesthesia: a feasibility study. Br J Anaesth. 2007;98:682-6. [PubMed]

[6]. Tzovaras G, Fafoulakis F, Pratsas K, Georgopoulou S, Stamatiou G, Hatizitheofilou C. Spinal vs. general anesthesia for laparoscopic cholecystectomy; interim analysis of a controlled randomized trial.Arch Surg. 2008;143:497-501. [PubMed]

[7]. van Zundert AA, Stultiens G, Jakimowicz JJ, van den Borne BE, van der Ham WG, Wildsmith JA. Segmental spinal anesthesia for cholecystectomy in a patient with severe lungs disease. Br J Anaesth.2006;96:464-6. [PubMed]

[8]. Pursnani KG, Bazza Y, Calleja M, Mughal MM. Laparoscopic cholecystectomy under epidural anesthesia in patients with chronic respiratory disease. Surg Endosc. 1998;12:1082-4. [PubMed]

[9]. Hirvonen EA, Poikolainen EO, Paakkonen MF, Nuutinen LS. The adverse hemodynamic effects of anesthesia, head-up tilt, and carbon dioxide pneumoperitoneum during laparoscopic cholecystectomy.Surg Endosc. 2000;14:272-7. [PubMed]

[10]. El-Dawlatly Hemodynaic profile durings laparoscopic cholecystectomy versus laparoscopic bariatric surgery: the impact of morbid obesity. Middle East J Anesthesiol. 2007;19:51-60. [PubMed]

[11]. Barczynski M, Herman RM. Low pressure pneumoperitoneum combined with intraperitoneal saline washout for reduction of pain after laparoscopic cholecystectomy: a prospective randomized study. Surg Endosc. 2004;18:1368-73. [PubMed]

[12]. Hamad MA, El-Khattary OA. Laparoscopic cholecystectomy under spinal anesthesia with nitrous oxide pneumoperitoneum: a feasibility study. Surg Endosc. 2003;17:1426-8. [PubMed]

[13]. Sandhu T, Yamada S, Ariyakachon V, Chakrabandhu T, Chongruksut W, Ko-iam W. Low pressure pneumopertoneum versus standard pneumoperitoneum in laparoscopic cholecystectomy, a prospective randomized clinical trial. Surg Endosc. 2009;23:1044-7. [PubMed]

[14]. Barczynski M, Herman RM. The usefulness of low-pressure pneumoperitoneum in laparoscopic surgery. Folia Med Cracov. 2002;43:435. [PubMed]

[15]. Barczynski M, Herman RM. A prospective randomized trial on comparison of low pressure (LP) and standard pressure (SP) pneumoperitoneum for laparoscopic cholecystectomy. Surg Endosc.2003;17:533-8. [PubMed]

[16]. Rajesh S. Mane, Manjunath C. Patil, K. S. Kedareshvara, C. S. Sanikop. Combined spinal epidural anesthesia for laparoscopic appendectomy in adults: A case series. Saudi J Anaesth. 2012 Jan-Mar; 6(1): 27-30. [PubMed]

[17]. Ciofolo MJ, Clergue F, Seebacher J, Lefebvre G, Viars P. Ventilatory effects of laparoscopy under epidural anesthesia. Anesth Analg. 1990;70:357-61. [PubMed]

[18]. Manoranjan Kar, Jugal K. Kar, Bibhas Debnath. Experience of Laparoscopic Cholecystectomy Under Spinal Anesthesia with Low-pressure Pneumoperitoneum - Prospective Study of 300 Cases. Saudi J Gastroenterol. 2011 May-Jun; 17(3): 203-207. [PubMed]

Table I: Patients detail and results

\begin{tabular}{|l|l|}
\hline \multicolumn{1}{|c|}{ Total No. of patients } & 35 \\
\hline \multicolumn{1}{|c|}{ female } & 14 \\
\hline Mean age & 21 \\
\hline Mean BMI & $22.5 \mathrm{yrs}(\mathrm{range} 18$ to 35$)$ \\
\hline Required conversion to open technique & $18.35 \mathrm{~kg} / \mathrm{m}^{2}$ (range 15.18 to 25.25$)$ \\
\hline Required conversion to general anaesthesia & 2 patients \\
\hline Bradycardia & 0 \\
\hline Transient Hypotension & 0 \\
\hline Mild shoulder pain & 12 patients \\
\hline Severe shoulder pain & 17 patients \\
\hline Mean operative time & 16 patients \\
\hline Postural headache & 25.35 minutes (range $18-45)$ \\
\hline Duration of hospital stay & 05 patients \\
\hline Cosmatic satisfaction & 24 hrs \\
\hline Wound infection or any other complication & Almost $100 \%$ patients \\
\hline
\end{tabular}

